\title{
A IMPORTÂNCIA DAS PRÁTICAS CONSTRUTIVAS NOS CANTEIROS EXPERIMENTAIS EM CURSOS DE ARQUITETURA E URBANISMO
}

\author{
THE IMPORTANCE OF BUILDING PRACTICES IN EXPERIMENTAL SITES IN ARCHITECTURE \\ AND URBANISM COURSES
}

\author{
Sofia Araújo Lima Bessa 1 \\ Lisiane Ilha Librelotto ${ }^{2}$ \\ ' Universidade Federal de Minas Gerais, \\ Belo Horizonte, MG, Brasil, \\ sofiabessa@ufmg.br \\ 2 Universidade Federal de Santa Catarina, \\ Florianópolis, SC, Brasil, \\ lisiane.librelotto@arq.ufsc.br
}

\begin{abstract}
Contribuição dos autores:
SALB: conceituação, curadoria de dados, análise formal, investigação, metodologia, validação, visualização, escrita - rascunho original, escrita - revisão e edição. LIL: conceituação, curadoria de dados, análise formal, investigação, metodologia,

validação, visualização, escrita - revisão e edição.
\end{abstract}

Fomento: Não houve fomento

Declaração de conflito: nada foi declarado.

Editor Responsável:

Sidney Piochi Bernardini (D)

\begin{abstract}
Resumo
A dicotomia entre a arte e a técnica, o abstrato e a materialidade, nem sempre estiveram presentes na formação e no exercício da arquitetura. Essa temática, apesar de remontar ao período Renascentista, ainda continua presente nas discussões acerca do saber fazer na arquitetura atualmente, apesar das reflexões acerca do tema, iniciadas, de forma mais contundente, com Sérgio Ferro e Vilanova Artigas. Os objetivos deste artigo são: i) apresentar o estado da arte dos canteiros experimentais nos CAU em atividade no país; ii) discutir a eficiência e a eficácia dos canteiros experimentais nesse contexto; iii) apresentar dois relatos de experiências práticas em cursos de arquitetura; e iv) apresentar e discutir os requisitos que devem ser observados em busca do sucesso das atividades nesses canteiros. Ao final, pode-se perceber que as visões convergem para que o canteiro experimental possa ser um local de desenvolvimento de atividades criativas, diferentemente daquelas desenvolvidas nos canteiros de obras e nos laboratórios tradicionais de materiais de construção civil. Nas atividades em canteiros experimentais, o resultado não é tão importante quanto o aprendizado. Os pontos mais divergentes referem-se à necessidade de formalização do canteiro nos respectivos cursos de arquitetura e urbanismo. Alguns autores colocam a atividade como paralela à formação do arquiteto, outros como complementar e alguns como atividade formal integrada ao currículo. No entanto, pode-se entender que os canteiros experimentais são espaços eficientes e eficazes, capazes de fomentar o desenvolvimento de atividades criativas e inovadoras, além de possibilitar a existência de relações professor/aluno mais dialógicas.
\end{abstract}

Palavras-chave: canteiro experimental, prática, tecnologia de arquitetura.

\begin{abstract}
The contrast between art and technique, the abstract and materiality, were not always present in the formation and exercise of architecture. Despite going back to the Renaissance period, this theme is still present in discussions about the know-how in architecture today, despite the reflections on the theme initiated with Sérgio Ferro and Vilanova Artigas. The objectives of this article are: i) to present the state of the art of the experimental sites in the Architecture and Urbanism courses that are active in Brazil; ii) discuss the efficiency and effectiveness of the experimental sites in this context; iii) to present two reports of practical experiences in architecture courses, and iv) to present and discuss the requirements that must be observed in search of the success of the activities in these sites. In the end, it can be seen that the visions converge so that the experimental site can be a place for the development of creative activities, differently from those developed in construction sites and traditional laboratories of civil construction materials. In activities on experimental sites, the result is not as important as learning. The most divergent points refer to the need to formalize the construction site in the respective courses in architecture and urbanism. Some put the activity in parallel with the architect's training, others as a complement, and some as a formal activity inserted in the curriculum. However, it can be understood that the experimental sites are efficient and effective spaces. They may be capable of fostering the development of creative and innovative activities and enabling the existence of more dialogical teacher-student relationships.

Keywords: experimental site, practice, architecture technology.
\end{abstract}

How to cite this article:

BESSA, S. A. L.; LIBRELOTTO, L. I.. A importância das práticas construtivas nos canteiros experimentais em cursos de arquitetura e urbanismo. PARC Pesquisa em Arquitetura e Construção, Campinas, SP, v. 12, p. e021028, 2021. ISSN 1980-6809. DOI: http://dx.DOI.org/10.20396/parc.v12n00.8660850 
BESSA, S. A. L.; LIBRELOTTO, L. I.

A importância das práticas construtivas nos canteiros experimentais em cursos de arquitetura e urbanismo

\section{Introdução}

A dicotomia entre a arte e a técnica, o abstrato e a materialidade, nem sempre estiveram presentes na formação e exercício da arquitetura. Com a preocupação de (re) aproximá-las - arte e técnica - os Cursos de Arquitetura e Urbanismo (CAU) vêm adotando, entre outras medidas, a prática em canteiros experimentais.

Os espaços de vivência construtiva manifestam-se como uma reinvindicação dos futuros arquitetos frente a uma estrutura curricular estabelecida e como um mecanismo de reforço dessa indissociabilidade, apontando para a necessidade de uma formação mais prática, na qual as ideias possam tomar forma no factível e sofram a influência da forma, do peso e da condição do material.

O Canteiro Experimental, ou os também chamados de Canteiros Livres (denominação empregada em Pompéia (2006) - que ressalta a ocorrência conjunta destes instrumentos com os laboratórios de habitação em cursos de arquitetura), dentro de uma Escola de Arquitetura e Urbanismo, pode assumir diferentes significados: i) o vínculo (perdido) entre a arquitetura e a sua dimensão social e econômica; ii) a reaproximação entre o trabalho manual e o intelectual; iii) a oportunidade de sentir estímulos sensoriais físicos no ato de construir e conceber; iv) uma vivência em processos de trabalho de ajuda mútua; v) um local de experimentação de técnicas construtivas e de materiais de construção; ou mesmo, a conquista da compreensão de que o desenho é apenas um método de representação que procura dialogar com o canteiro visando à construção da arquitetura de fato (SILVOSO et al., 2017).

É neste ponto que se torna necessária a (re)união da arte e da técnica ainda na formação do arquiteto e urbanista, o que pode ser alcançado pelo exercício prático em canteiros experimentais, para que o aluno/projetista possa tomar a melhor decisão de forma a fundir o belo ao racional, associada às restrições que o ambiente físico possa impor à criatividade. Ou mesmo, pode-se pensar em como a criatividade pode moldar os recursos físicos disponíveis de forma inovadora, para se alcançar o resultado imaginado.

Por meio da análise de 24 experiências conduzidas em canteiros experimentais em CAU no Brasil, este artigo discute a importância das experiências práticas para a formação do arquiteto e urbanista. De forma a entender melhor esta necessidade, detalha-se a realidade de experimentos conduzidos pelas pesquisadoras em diferentes contextos institucionais.

Assim, os objetivos deste artigo são: i) apresentar o estado da arte dos canteiros experimentais nos CAU em atividade no país; ii) discutir a eficiência e a eficácia dos canteiros experimentais nesse contexto; iii) apresentar dois relatos de experiências práticas em cursos de arquitetura; e iv) apresentar e discutir os requisitos que devem ser observados em busca do sucesso das atividades nesses canteiros.

Como forma de alcançar os objetivos propostos, são apresentadas as visões de Artigas (1989), Arantes (2002), Benoit (2002), Ronconi (2005) e outros nomes importantes para a discussão do tema dos canteiros experimentais nos CAUs brasileiros. Desta forma, estabelece-se um histórico e uma linha do tempo do surgimento dos cursos e as experiências em canteiros experimentais, assim como se aprofunda na narrativa de casos experimentais que podem servir de inspiração para o ensino, a pesquisa ou a extensão. 
BESSA, S. A. L.; LIBRELOTTO, L. I.

A importância das práticas construtivas nos canteiros experimentais em cursos de arquitetura e urbanismo

\section{Fundamentação}

Sobre a separação entre a arte e a técnica, dizia Artigas (1989) que seria inexistente, assim como o desenho e a ação. Essa separação foi inserida no processo de criação recentemente, é pós-renascentista: ... "a separação entre técnica e arte é, quando aparece no Renascimento, ou no fim da Baixa Idade Média, a dificuldade de dividir técnicas e artes mecânicas de belas-artes" e que "então, teríamos de pautar essa diferença que se insiste entre técnica e arte e, especificamente, ligando ao campo da arquitetura, arquitetura como arte, arquitetura como técnica, verificar que há aqui uma violência".

Com a Revolução Industrial, a contradição entre arte e técnica encontra uma nova instabilidade, "transformando-se em crise aguda". Não por culpa do desenho, ressalva Artigas, mas pelo "aparecimento da máquina, de um lado, e do pensamento romântico, do outro". Arte e indústria aparecem, então, em "oposição irredutível" (ARANTES, 2002).

Desta forma, Artigas (1989) constatou que técnica e arte, especificamente no campo da arquitetura, "são inseparáveis, como foram no passado na Grécia, em Roma e na Idade Média...".

Desde os anos 1960, no entanto, Sérgio Ferro passou a analisar criticamente a arquitetura, com uma visão simultaneamente disciplinar e ideológica, identificando na arquitetura moderna uma separação entre o desenho e o canteiro de obras; entre o arquiteto e o construtor - uma separação forçada que, segundo o autor, é um dispositivo de dominação classista e ideológica (AMARAL, 2020). Ao lado de Rodrigo Lefèvre (1938-1984) e Flávio Império (1935-1985), o arquiteto e artista plástico Sérgio Ferro fez parte de um dos momentos mais criativos da arquitetura brasileira, que se desenvolveu nos anos 1960, sob o princípio da vinculação essencial entre a inovação estética e a práxis política revolucionária (BENOIT, 2002).

Já em seu primeiro texto de maior fôlego, de 1969, Sérgio Ferro sintetizou as críticas até então formuladas pelo grupo, chamando a atenção para a reprodução vazia de significado à qual a arquitetura dos mestres modernos havia chegado. $O$ novo centro da discussão, para pensar novas práticas, é a divisão do trabalho, que deve ser visto a partir das relações no canteiro (AMARAL, 2020). Para que tal encontro aconteça, ambos, arquitetos e trabalhadores da construção civil, precisariam "reaprender o que já foi aprendido" numa forma diferente de se relacionar (DIEDERICHSEN, 2012).

Canteiro-ateliê ou canteiro-escola são visões que o grupo da Arquitetura Nova trazem para a arquitetura do futuro. O canteiro torna-se o espaço onde se produz ideias, formam-se pessoas para de fato consolidar outra prática de arquitetura, com função social plena (FERRO, 2008; LOTUFO, 2014).

A discussão de Ferro transcende ao que seriam as atividades dos canteiros experimentais, como locais de formação dos estudantes de arquitetura (ensejando uma aproximação da teoria com a prática), e é transposta para o campo da poética da economia - a recusa do revestimento, a racionalização do trabalho manual no canteiro a subalternização do desenho à lógica construtiva - não como uma estética, mas como uma proposta ética e política de mediação entre o projeto e a obra (AMARAL, 2020).

Experiências de construção prática nas faculdades de arquitetura existiram, de forma isolada, desde a década 1970, mas a maioria não teve continuidade nos cursos de Arquitetura e Urbanismo (SILVOSO; CORDEIRO; ALBUQUERQUE, 2017). 
BESSA, S. A. L.; LIBRELOTTO, L. I.

A importância das práticas construtivas nos canteiros experimentais em cursos de arquitetura e urbanismo

A necessidade de implementação de canteiros experimentais foi apontada formalmente, pela primeira vez no Brasil, em 1994. No documento que serviu de base para a proposição das Diretrizes Curriculares Nacionais (DCNs) para os cursos de Arquitetura e Urbanismo (CAU) brasileiros, registrou-se a necessidade da oferta de atividades de ensino, pesquisa e extensão oportunizando a participação de estudantes em escritórios modelo de projeto de arquitetura e urbanismo; canteiros de obras de arquitetura e urbanismo; e núcleos ou laboratórios de habitação e habitat (CEAU, 1994).

Ronconi (2005) afirma que "[...] o uso do canteiro experimental é sempre uma reivindicação de grande parte dos estudantes. Reivindicação que pode ser observada em seu aspecto generalizante, em todos os encontros promovidos pelos estudantes de arquitetura e urbanismo, quando o tema, necessariamente, ilustra algumas atividades."

O arquiteto Vitor Lotufo foi um dos pioneiros em experiências de construção em escala 1:1, utilizando diversos materiais, numa atividade de prática projetual e construtiva no começo da década de 1980 . No entanto, essas atividades haviam iniciado um pouco antes, com os professores Ernesto Boccara e Izaak Vaidergorn, nos anos 1979/1980, na disciplina de teoria da arquitetura, na Faculdade de Arquitetura e Urbanismo da PUC de Campinas. Esta atividade seria retomada por Vitor Lotufo e o arquiteto João Marcos de Almeida Lopes, na experiência do primeiro canteiro experimental nesse mesmo curso, em 1995, conhecido como Platô (RONCONI, 2005). O Platô foi demolido em 26 de março de 2005 e esse evento foi marcado por protestos estudantis registrados no Jornal da PUC Campinas (BORGES, 2005).

Do documento que institui as DCNs e do roteiro avaliativo, resultou a proposição das Diretrizes Curriculares Gerais (Portaria № 1.770 - MEC, de 21 de dezembro de 1994, revogada pela Resolução $n^{\circ} 6$, de 2 de fevereiro de 2006) para os cursos de Arquitetura e Urbanismo, que acabou por mencionar apenas, de forma genérica, a necessidade da prática construtiva, sem empregar o termo canteiro experimental. Essa omissão se repetiu nas revisões das DCNs para os CAU de 2006 e de 2010. Destacou-se, apenas, a necessidade do conhecimento sobre planejamento e organização de canteiros de obras para os profissionais arquitetos e urbanistas, a necessidade de que o projeto pedagógico inclua a visita nestes espaços e que o domínio especializado dos materiais, sua resistência e a estabilidade das construções integre os conteúdos curriculares.

A Norma Regulamentadora 18 (NR18) (BRASIL, 2020) define as instalações e as condições de execução dos trabalhos em canteiro de obras. Embora o canteiro experimental possa ser entendido, também, como um espaço para realização da prática construtiva, distingue-se do primeiro conceito pelo seu caráter experimental, no qual em um prima-se pelo cumprimento das normativas e da legislação vigente e, no outro, pode-se servir como um desafio às normativas ou mesmo uma forma de questionamento pelo fazer diferente e, desta maneira, servir como quebra de paradigmas ou proposição de novos padrões técnicos, embora os cuidados com as condições do trabalho devam permanecer (saúde, segurança e planejamento do espaço).

De qualquer maneira, independente da obrigatoriedade formal e legal, os canteiros experimentais podem ser considerados importantes recursos a serem utilizados na formação discente. Ronconi (2005) apontou trabalhos realizados na FAU/USP e elaborou uma distinção entre os canteiros experimentais e os canteiros de obras, ao mesmo tempo em que os estabeleceu como essencialmente instrumentos de investigação que não podem ser confundidos com o conhecimento curricular técnico 
BESSA, S. A. L.; LIBRELOTTO, L. I.

A importância das práticas construtivas nos canteiros experimentais em cursos de arquitetura e urbanismo

necessário à formação do arquiteto e nem com os laboratórios de materiais e de construção já implementados.

Por outro lado, outras experiências mais recentes, como a da Universidade Federal do Mato Grosso do Sul (UFMS), instituíram o canteiro experimental como um laboratório, comum a cursos de engenharia, arquitetura e geografia (FAENG, 2019), com estrutura bem definida, que atua em ensino, pesquisa e extensão.

Na Figura 1 pode-se perceber a linha temporal do surgimento dos primeiros CAU no Brasil e a criação dos principais canteiros experimentais. Constam apenas os experimentos nos quais foi possível identificar datas e registros e, de forma alguma, pode ser entendida como definitiva.

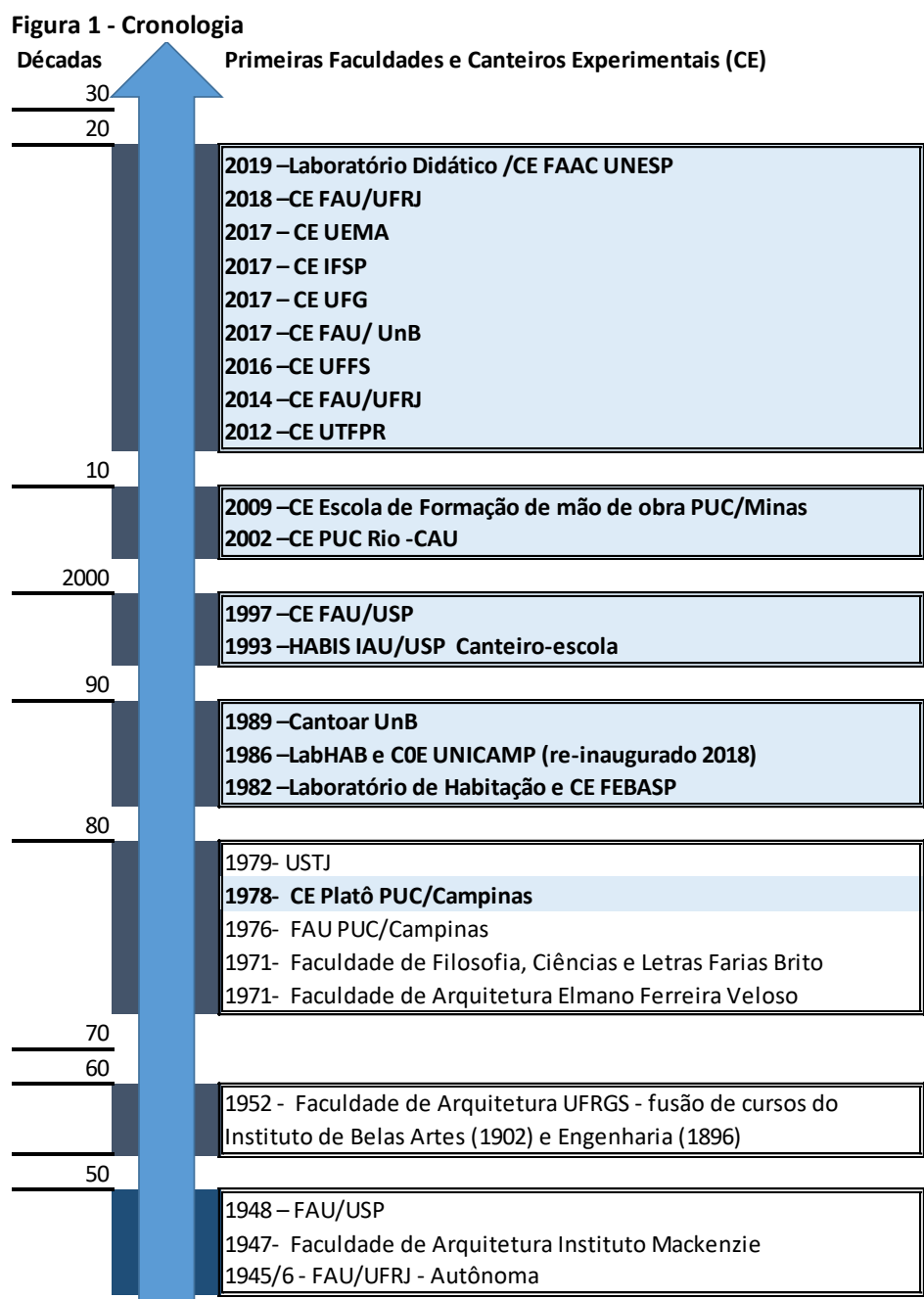

Outros CE, sem registro da data de criação:

UFBA/Tectônica (s.d.), UFPR(s.d), Canteiro Experimental da

FAENG/UFMS, CE Universidade Santa Úrsula - USU e, CE de Obras UFOP

e Anhembi.

Foram ainda encontrados experimentos em canteiros ainda informais

nos CGAUs, como na UFSC (desde 2011) , Prática de Canteiro

Experimental noIFSP e UFMG

1816-FAU/UFRJ Academia de Belas Artes

1800

Fonte: as autoras. 
BESSA, S. A. L.; LIBRELOTTO, L. I.

A importância das práticas construtivas nos canteiros experimentais em cursos de arquitetura e urbanismo

Os canteiros experimentais foram temas de teses, dissertações e trabalhos de conclusão de curso. Minto (2009) apresentou a evolução da implementação dos canteiros experimentais nos CAUs brasileiros baseando-se no primeiro registro feito por Ronconi (2002) em sua tese de doutorado.

Saramago e Lopes (2009) destacaram algumas experiências históricas no sentido da experimentação prática, além das experiências, descritas a seguir em maiores detalhes, da PUC/Campinas e da PUC/MG:

- Faculdade de Arquitetura Elmano Ferreira Veloso, em São José dos Campos, entre 1971 e 1975, que integrou disciplinas de música, cinema, história e tecnologia em aulas teóricas pela manhã e práticas à tarde;

- Faculdade de Filosofia, Ciências e Letras Farias Brito, início da década de 70, que solicitava a elaboração de modelos na escala 1:1, de maneira que o aumento da escala dos protótipos resultasse em "um comprometimento com as questões materiais e físicas da realidade";

- Universidade São Judas Tadeu (USJT), final da década de 70, que implementou um laboratório de estruturas articulado a um conjunto de disciplinas voltadas à experimentação material de soluções;

- A experiência do Curso de Arquitetura da Faculdade de Belas Artes de São Paulo (FEBASP) - Os Laboratório de Habitação e canteiro experimental implementados em 198P2, nesta universidade particular, foram precursores de uma série de outros laboratórios que o seguiram. Este laboratório é citado como pioneiro na tarefa de levar a formação do arquiteto para além dos muros da universidade (POMPÉlA, 2006). Essa mesma autora destaca que este laboratório chegou a ter um pequeno canteiro para experimentos e se dedicou mais a assessoria técnica para população de baixa renda, mas teve impacto muito significativo no histórico dos CAU do Brasil.

Sobressaem-se, no contexto atual, 24 experiências que podem ser destacadas como atividades presentes em canteiros experimentais (ou canteiros livres) nas instituições listadas a seguir:

- Instituto Federal de São Paulo;

- Pontifícia Universidade Católica de Campinas (PUC-CAMPINAS, 2019);

- Faculdade de Engenharia Civil, Arquitetura e Urbanismo na Universidade Estadual de Campinas (FECFAU-UNICAMP, 2019);

- Faculdade de Arquitetura e Urbanismo e Instituto de Arquitetura e Urbanismo da Universidade de São Paulo (CANTEIRO EXPERIMENTAL, 2004; FAU-USP, 2019);

- Faculdade de Arquitetura e Urbanismo da Universidade Presbiteriana Mackenzei (FAU-MACKENZIE, 2014);

- Faculdade de Arquitetura e Urbanismo da Universidade Federal do Rio de Janeiro (FAU-UFRJ, 2019);

- Faculdade de Arquitetura e Urbanismo da Universidade de Brasília;

- Pontifícia Universidade Católica do Rio de Janeiro (PUC-RIO, 2020);

- Pontifícia Universidade Católica de Minas Gerais (PUC-MINAS, 2009 e 2019); 
BESSA, S. A. L.; LIBRELOTTO, L. I.

A importância das práticas construtivas nos canteiros experimentais em cursos de arquitetura e urbanismo

- Faculdade de Arquitetura, Artes, Comunicação e Design da Universidade Estadual Paulista em Bauru e Presidente Prudente (FAAC-UNESP, 2019);

- Faculdade de Arquitetura e Urbanismo da Universidade Federal da Bahia (TECTÔNICA, 2020);

- Universidade Federal da Fronteira Sul, Campus Erechim (UFFS, 2020);

- Universidade Federal de Goiás (UFG, 2017);

- Universidade Tecnológica do Paraná;

- Universidade Federal do Paraná (UFPR, 2020);

- Universidade Estadual do Maranhão (UEMA, 2020);

- Universidade Federal da Integração Latino-Americana;

- Universidade Federal do Mato Grosso do Sul;

- Universidade Estadual de Maringá;

- Universidade Federal de Viçosa;

- Universidade Federal de Santa Catarina; e

- Faculdade Anhembi Morumbi (PORTAL ANHEMBI, 2019).

Mais informações sobre estes canteiros podem ser encontradas em diversas fontes (BORBA, 2018; BORGES, 2005; CANTEIRO ESCOLA TBC, 2019; EVEN3, 2020; HABIS, 2020; MINTO, 2019; NASCIMENTO; SILVOSO; GONÇALVES, 2017; POMPÉIA, 2006)

\section{Eficácia, eficiência e efetividade do canteiro experimental}

Nos canteiros experimentais, o resultado não é tão importante quanto o caminho de aprendizado percorrido. De acordo com Nascimento, Silvoso e Gonçalves (2017),

“(...) o Canteiro Experimental deve ser um espaço de realização de exercícios e experimentos construtivos tendo em seu âmago a reflexão sobre a prática. Não se assemelha aos laboratórios de construção na medida em que o foco não deve ser o resultado e sim o processo. É por meio dele que os estudantes deverão desenvolver suas habilidades".

O Canteiro Experimental representa, em uma de suas facetas, um espaço de experimentação construtiva, mostra-se com potencial para tornar-se um importante instrumento pedagógico para o ensino de estrutura e dos componentes do edifício, quando permite a realização de atividades práticas sem muita preocupação com o resultado final.

Como ambiente pedagógico, o canteiro se apresenta como um local em que as relações professor/aluno podem ser mais dialógicas. Com os desafios implícitos durante a construção (ou os processos construtivos experimentais), a tentativa de resolução dos problemas desperta nos alunos a curiosidade e a necessidade de se encontrar soluções (LOTUFO, 2014).

Pode-se estender a validade da prática para todas as etapas do processo construtivo, no qual o futuro profissional pode criar a obra, projetá-la através de técnicas manuais ou computacionais, verificar a compatibilidade dos sistemas e dos materiais a sua proposta para posteriormente constatar na realidade construtiva, os erros e os acertos. 
BESSA, S. A. L.; LIBRELOTTO, L. I.

A importância das práticas construtivas nos canteiros experimentais em cursos de arquitetura e urbanismo

Pisani et al. (2009) colocaram a necessidade de repensar o ensino de arquitetura através do resgate do fazer arquitetônico diante das "práticas reflexivas consagradas e hegemônicas no ensino de arquitetura e urbanismo das últimas décadas". Este resgate busca um novo equilíbrio entre o fazer e o pensar, em especial, a simultaneidade do pensar fazendo e o fazer pensando, como elementos estruturadores de uma metodologia de ensino.

Além disso, Pisani et al. (2009), após uma análise das DCNs para os CAU, na versão de 2006, pontuaram o distanciamento dos cursos de arquitetura em relação ao saberfazer e destacaram a ausência da indicação nas DCN para que os canteiros experimentais possam servir como um instrumento metodológico desta aproximação:

"Estas considerações permitem entrever que, de modo geral, as escolas brasileiras vêm se colocando na situação de privilegiar desproporcionalmente, no ensino do projeto de arquitetura e urbanismo em suas várias escalas, uma espacialidade imaterial ou, mais grave, a imaterialidade do espaço." (PISANI et al., 2009)

No que se refere à eficiência do canteiro enquanto um recurso didático e de formação profissional, entendendo-se esta como a melhor maneira possível de empregar os recursos disponíveis para a formação do arquiteto e urbanista, o canteiro é o instrumento que confronta ou integra a criatividade ao domínio da técnica e, sem dúvida, pode levar o aluno a um melhor entendimento do comportamento do material de forma isolada, ou de forma conjunta enquanto sistema, e pode aproximá-lo da comunidade e de problemas reais. Desta forma é eficiente, pois atinge o objetivo da formação do arquiteto no momento que este integra o plano/projeto/arte à técnica.

Como eficácia, diferentemente da eficiência, busca-se que o canteiro traga à formação do arquiteto ou de outros profissionais (porque pode sim se aplicar em outras áreas do conhecimento) o objetivo correto na forma da agregação de valor, ou seja, pensar como deve ser a formação do arquiteto para a solução dos problemas complexos que se apresentam atualmente, como por exemplo, a sustentabilidade.

Desta forma, parece que o canteiro experimental é o espaço ideal para a busca de inovações, principalmente no que tange à responsabilidade técnica profissional. Não é só no mercado que as questões da responsabilidade profissional surgem. Um docente que ensina em um curso de arquitetura, engenharia ou outro qualquer tem responsabilidade também pela formação do aluno. De uma ou de outra forma, essa responsabilidade profissional recai sobre o uso correto da técnica e do material (quando já existirem normativas) ou na busca da melhor solução técnica (pesquisa e inovação), sendo esta última bastante aplicável no canteiro experimental.

De qualquer modo, sendo o canteiro apto a promover a eficiência e a eficácia, no ensino, e a apreensão do conhecimento para o profissional, é desta forma efetivo. A efetividade pode ser conceituada com a habilidade de ser simultaneamente eficiente e eficaz.

\section{Narrativa dos casos}

Nesse tópico, foram apresentados dois relatos de experiências didáticas que tentaram interligar a questão do "saber-fazer" e do "aprender-fazendo", tão importantes nos cursos de arquitetura e urbanismo brasileiros, na UFMG e na UFSC. Esses relatos podem ser somados aos demais 24 relatados neste trabalho.

Esses relatos foram escolhidos pelas autoras a partir de suas experiências em atividades experimentais, em conjunto com outros docentes, nas quais pode-se evidenciar a aquisição de habilidades, pelos acadêmicos, por conta das atividades 
BESSA, S. A. L.; LIBRELOTTO, L. I.

A importância das práticas construtivas nos canteiros experimentais em cursos de arquitetura e urbanismo

práticas desenvolvidas. Esse ganho, segundo as autoras, não poderia ter sido obtido em atividades meramente teóricas, nas quais não se observa a tentativa e o erro, a observação e a intervenção, presentes nos espaços de experimentação.

Apesar de serem experiências muito expressivas, ainda são incipientes. Ao todo, no Brasil, estão em atividade mais de 800 cursos de arquitetura e urbanismo, sendo 249 com conceitos 3 a 5 no Exame Nacional de Cursos - ENADE e com oferta presencial (MEC, 2021). As experiências práticas em canteiros experimentais podem ser encontradas em menos de 30 destes, e restrito, portanto, a $12 \%$ do total de cursos melhor pontuados, segundo este índice.

Relato 1 - Experiências de ensino na Escola de Arquitetura/ UFMG

Tradicionalmente, a formação dos arquitetos e urbanistas na Escola de Arquitetura da Universidade Federal de Minas Gerais (EA/UFMG) vem sendo pautada, nas últimas três décadas, por uma relação de ensino-aprendizagem baseada quase exclusivamente na transferência da informação. Além disso, pode ser observada uma separação curricular e pedagógica entre as informações abordadas nas disciplinas de desenvolvimento de projeto, tanto arquitetônico como em escala urbana, como nas disciplinas voltadas às questões técnicas e materiais. Outro fato importante é que as disciplinas de caráter técnico estão pautadas em abordagens quase sempre teóricas ao longo de todo currículo, com poucas inserções práticas (BESSA; LOPES; LOURA, 2018).

A disciplina optativa "Práticas projetuais e construtivas associadas", que foi ofertada pela primeira vez em 2018 por três professoras de dois departamentos distintos e teve como objetivo buscar interligar a questão projetual com a prática dos sistemas construtivos.

Num primeiro momento, elementos da arquitetura de terra foram usados como articulação, tanto pela facilidade em relação à obtenção dos materiais, como por conta da sustentabilidade envolvida na adoção desses materiais em projetos de arquitetura. Essa escolha também ocorrei por conta da transferência de tecnologia para ocupações urbanas, pois as técnicas de construção com terra são de mais fácil execução e de disponibilidade para os moradores.

A proposta, até então inovadora na EA/UFMG, consistiu na articulação de dois tipos de conhecimentos relacionados aos saberes necessários para a construção do ambiente, a tecnologia e o projeto, e foi organizada em dois módulos ministrados concomitantemente: o Módulo Projetual (MP), ofertado pelo Departamento de Projetos (PRJ) e o Módulo Tecnológico (MT), ofertado pelo Departamento de Tecnologia do Design, da Arquitetura e do Urbanismo (TAU), ambos departamentos da EA/UFMG (LOPES; LOURA; BESSA, 2018).

Cada disciplina dispôs de 30 de aula e foi desenvolvida em ambientes distintos: nas salas de aulas da EA/UFMG (MP) e no Núcleo de Pesquisas em Materiais Sustentáveis NPMS (MT), laboratório de ensino e pesquisa ligado ao TAU e situado na Fazenda Modelo da UFMG, em Pedro Leopoldo (40 km distante do centro de Belo Horizonte).

A articulação entre os dois módulos (MT e MP) se deu por meio do bloco de terra comprimida (BTC) e do adobe, que foram produzidos pelos alunos no MT e utilizados como base do sistema construtivo do projeto desenvolvido no MP.

O MT teve como objetivo desenvolver atividades práticas com os alunos, que se iniciaram com a produção dos componentes construtivos e foram finalizadas com práticas construtivas de elementos de vedação (paredes e arcos). Já no MP, os alunos elaboraram um projeto arquitetônico para a sede de uma rádio comunitária (com um 
BESSA, S. A. L.; LIBRELOTTO, L. I.

A importância das práticas construtivas nos canteiros experimentais em cursos de arquitetura e urbanismo

espaço para biblioteca), que seria alocada em uma ocupação urbana autoconstruída, situada na cidade de Belo Horizonte.

Durante as atividades do MT, os alunos puderam vivenciar e desenvolver todas as etapas necessárias para produção de componentes de construção com terra, desde a retirada e o peneiramento do solo até a produção de prismas de alvenaria com encaixes e amarrações.

Durante as atividades didáticas, demonstrou-se aos alunos duas abordagens para composição dos materiais usados para produção dos componentes. Na abordagem tradicional, fez-se a estabilização do solo para adobe e para o BTC com areia. Já na abordagem inovadora, optou-se por substituir a areia, no adobe, por resíduos de construção e demolição (RCD) e no BTC, por rejeito de minério de ferro (RMF). Desta forma, foi possível imprimir materialidade e alternativas à discussão acerca da escassez da areia e dos demais agregados naturais.

Os alunos puderam vivenciar a produção de adobes em sua forma mais artesanal, analisando a consistência do solo, avaliando a quantidade de materiais adicionados, a moldagem dos elementos e realizando o acabamento final (Figura 2).

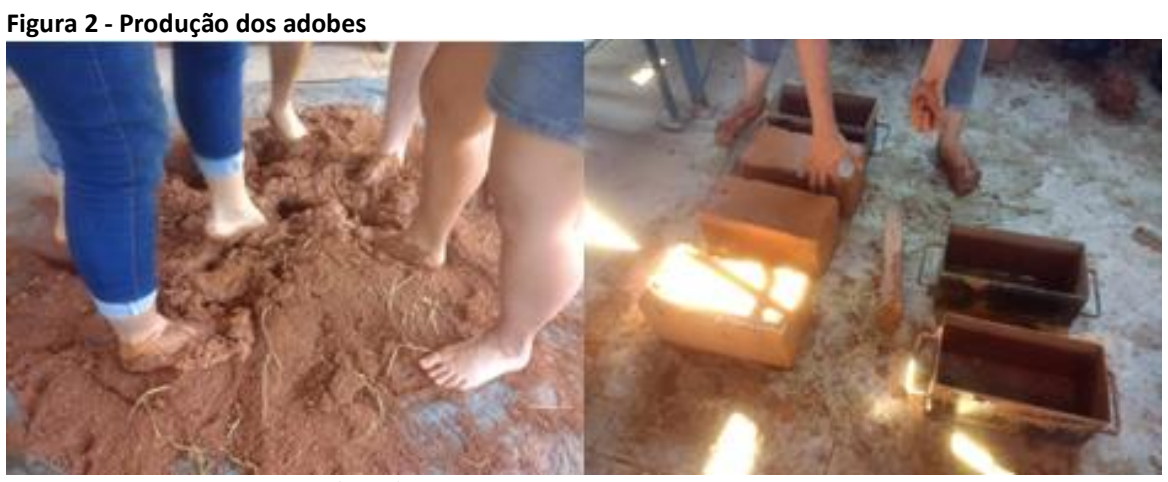

Fonte: Bessa, Lopes e Loura (2018)

Após a secagem (parcial) dos BTC e dos adobes, os alunos já iniciaram a construção de encaixes e de amarrações à semelhança das alvenarias convencionais e puderam trabalhar outros conceitos, como prumo, modulação e estabilidade, tão importantes na construção de vedações. Alguns alunos tiveram dificuldades técnicas à primeira vista, principalmente em relação às amarrações possíveis, contando com blocos e meio blocos. Logo perceberam como seria importante que os BTC também tivessem um bloco especial ( 1 bloco e meio) para melhor travamento de encontros em T. Ou seja, não basta produzir elementos em terra crua pensando na sustentabilidade das construções sem que haja um planejamento/paginação anterior à essa etapa que evite o desperdício e o corte desnecessário de blocos. Na Figura 3, pode-se perceber o esforço dos alunos na montagem das amarrações.

Para dar início ao MP, foram discutidas algumas questões que deveriam pautar o desenvolvimento do projeto: 1) indissociabilidade entre o espaço projetado e ambiente construído; 2) diretrizes da coordenação modular, horizontal e vertical e das amarrações das paredes em $\mathrm{T}$, L e cruz; 3) possibilidades formais para as aberturas e coberturas (arcos, abóbadas, etc.); 4) elementos estruturais para as aberturas (cintas, vergas e contravergas); 5) cuidados com as instalações prediais; 6) desafios de se incorporar na representação do projeto arquitetônico e seu processo construtivo.

Ainda assim, alguns grupos optaram por iniciar seus projetos sem considerar o uso do BTC, o que os levou ao redesenho tão logo perceberam que as medidas dos espaços projetados não poderiam estar dissociadas do tamanho do bloco. Rapidamente, 
BESSA, S. A. L.; LIBRELOTTO, L. I.

A importância das práticas construtivas nos canteiros experimentais em cursos de arquitetura e urbanismo

também se deram conta de que o projeto não poderia ser desenvolvido por meio de plantas apenas e que as elevações eram necessárias, afinal as decisões relativas às amarrações em $T$ ou $L$ precisavam ser feitas desde o início do desenho arquitetônico. Tratava-se de um raciocínio em três dimensões, no qual o processo construtivo deveria ser pensado juntamente com o projetual. Esse foi um fato novo para os alunos, acostumados a fragmentar o processo de projeto e dissociá-lo da sua execução.
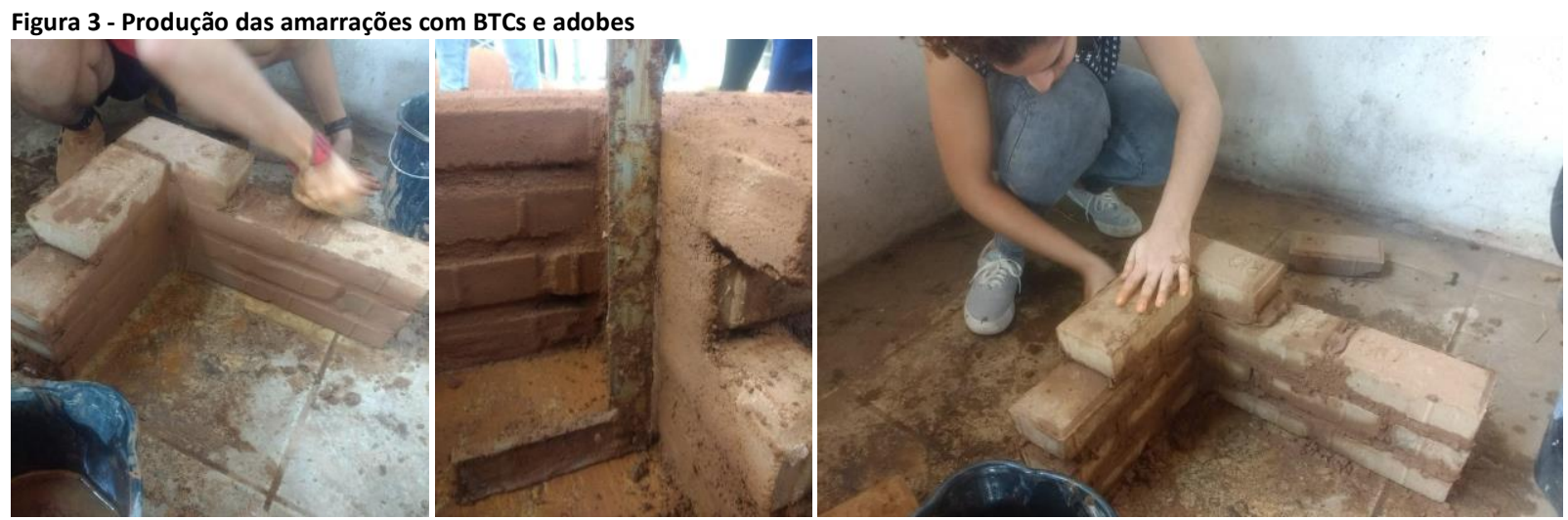

Fonte: Lopes, Loura e Bessa (2018).

Com relação aos avanços percebidos ao longo do $\mathrm{MP}$, a incorporação do BTC no desenvolvimento das propostas provocou um raciocínio projetual mais complexo e amplo, no qual os ditos detalhes construtivos passaram a ser pensados e resolvidos desde o início do processo. Quem, como e quais são as etapas de uma construção foram aspectos percebidos como sendo parte integrante do projeto arquitetônico (LOPES; LOURA; BESSA, 2018).

Partindo-se do pressuposto que somente se concebe uma boa solução projetual quando se entende como o espaço será construído, é de fundamental importância que os alunos de arquitetura e urbanismo tenham acesso a vivências práticas associadas às disciplinas projetuais.

Percebeu-se que, ao final do processo, os alunos se tornaram tecnicamente capazes de decidir pela construção em terra tendo em vista as demandas construtivas e projetuais desse tipo de solução. Muitos mitos negativos sobre o uso da terra foram desfeitos. Foi possível, também, apresentar a complexidade ligada a esse sistema construtivo, seus desafios tecnológicos, campos possíveis de pesquisa e negócios.

Relato 2 - Experimentações realizadas em disciplinas, em universidades públicas e comunitárias.

Desde 1999, a atuação docente em cursos de arquitetura e urbanismo, design e engenharias envolveu as atividades de experimentação desenvolvidas em diferentes instituições (pública e comunitária). São 20 anos de docência envolvendo experimentos, na forma de pesquisa e extensão vinculados ao ensino em canteiros experimentais formais e informais.

Dessa forma, são apresentados alguns dos experimentos que, de certa forma, ficaram registrados. São adicionados comentários sobre os objetivos e a abordagem utilizada com os alunos, destacando-se o relato discente sobre as experiências.

Nas imagens da Figura 4, são ilustrados alguns experimentos realizados em cursos de arquitetura e urbanismo. Os trabalhos foram conduzidos em disciplinas de sistemas construtivos (desde 1999) ou de tecnologia das edificações (a partir de 2011), em universidade comunitária ou em universidade pública. O tempo de produção dos 
BESSA, S. A. L.; LIBRELOTTO, L. I.

A importância das práticas construtivas nos canteiros experimentais em cursos de arquitetura e urbanismo

experimentos se estendia por diversas semanas e, em geral, cada objeto era produzido por grupos de mais de quatro alunos, podendo chegar a não mais do que 10 integrantes.

O objetivo proposto era a produção artística de algum objeto que pudesse servir ao ambiente urbano ou sugestão criativa / inovadora de habitações. A seleção dos materiais e técnicas construtivas empregadas era de livre escolha dos alunos. A ementa da disciplina era voltada para o emprego de sistemas construtivos e processos de execução em arquitetura: artesanal, misto e industrial; os tipos e aplicações dos diversos sistemas, relacionando-as com a arquitetura; a técnica construtiva e suas alternativas: potencialidades, restrições e implicações diversas.

Faziam parte da avaliação da disciplina a proposta e o resultado atingido, não pela estabilidade ou desempenho técnico, mas pela realização do proposto. A proposta deveria conter: a) Planta baixa e dois cortes, contendo cotas e dimensões. Em escala; b) Memorial descritivo e especificações técnicas. Descrição detalhada da técnica executiva a ser utilizada, desde a marcação/locação da obra até execução de revestimentos e acabamentos. Referências às normas técnicas, quando houvesse. Etapas da obra e cronograma para elaboração. c) Levantamento dos materiais necessários à execução - especificando marcas e tipo de material, local de compra, quantidade de material necessário e estimativa do custo.

O resultado era avaliado pela presença nas aulas práticas, empenho na realização da atividade e resultado alcançado frente à proposta realizada. Os resultados eram apresentados na data marcada, durante a aula, com explicação para a turma sobre a construção e o seu objetivo.

Após a apresentação da proposta de experimento, havia um tempo para aquisição/arrecadação de materiais. Muitos grupos utilizavam materiais que precisavam ser coletados em ferros - velho, em refugos de indústrias, entre outros rejeitos. Os materiais convencionais que podiam ser obtidos em lojas, normalmente eram adquiridos pela instituição, o que demandava o respeito aos prazos de entrega e especificações corretas para que a compra fosse realizada com sucesso. As atividades eram realizadas pelos alunos, como apoio da professora e de um técnico que auxiliava nas atividades mais difíceis e que exigiam maior domínio da técnica. Os equipamentos de segurança, de responsabilidade dos alunos, vestimentas adequadas e instruções de segurança eram repassados antes do início dos experimentos, mas nem sempre eram respeitados. Estimulava-se que as obras concluídas fossem entregues considerando-se a boa apresentação das mesmas e valorização da paisagem.

Os alunos ficavam responsáveis pela higiene e pela organização do espaço, pelo recolhimento e estocagem de materiais residuais e pela limpeza de ferramentas ao final e durante as atividades.

Ao longo dos anos, muitos experimentos foram realizados, muitas vezes com inovação por parte dos alunos. A criatividade da proposta ficava sob a responsabilidade dos alunos e perfil de formação. Uma lista dos experimentos realizados e imagens são apresentados na Figura 4:

a) a árvore - construção utilizando resíduos de obras;

b) o boi de mamão - registro da cultura local na prática arquitetônica e construtiva;

c) a arte abstrata, o conflito interno/ externo como objeto construtivo;

d) painéis pré-fabricados com miolo em EPS;

e) O congresso nacional como brinquedo (balanço) infantil; 
BESSA, S. A. L.; LIBRELOTTO, L. I.

A importância das práticas construtivas nos canteiros experimentais em cursos de arquitetura e urbanismo

f) A vaca Sílvia, como churrasqueira para se auto cozer.

Figura 4 - Experimentação em sistemas construtivos, alunos do CAU/UNISUL. De 1999 a 2010

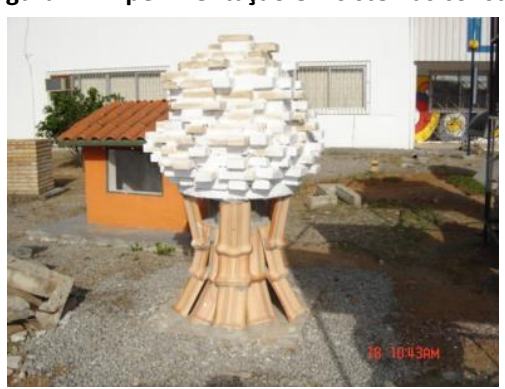

(A)

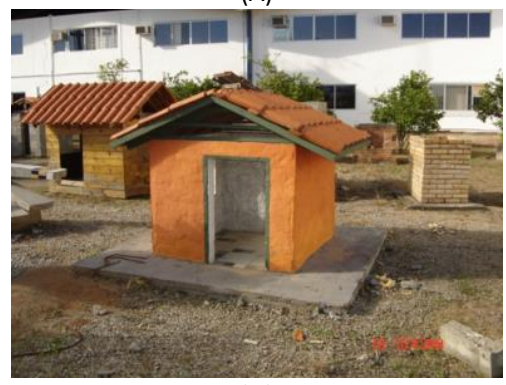

(D)

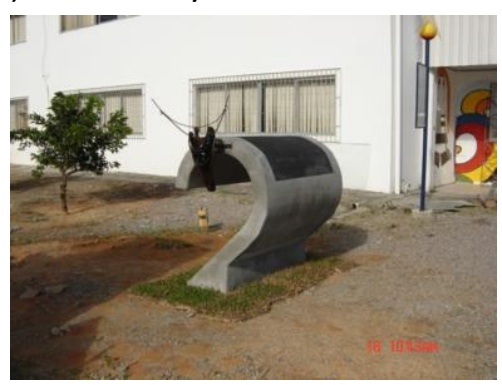

(B)

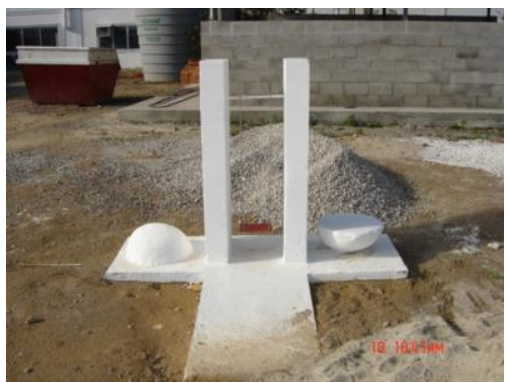

(E)

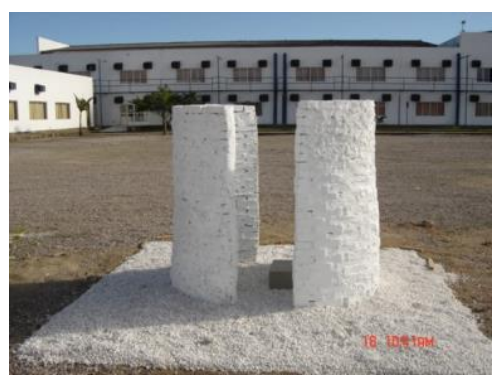

(C)

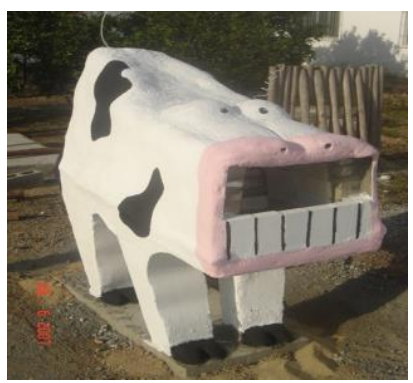

(F)

Fonte: Lisiane Librelotto (arquivos pessoais)

Outros experimentos realizados: escada com viga principal de eixo e degraus em balanço; banco em concreto moldado no local na forma de uma mão; mesa redonda com pilar circular ao centro e revestida com mosaico; mosaico com símbolo da arquitetura; lareira; lago artificial com plantas para tratamento da água; habitação em bambu; habitação em placas de concreto pré-moldado; habitação em madeira; habitação em madeira (toras roliças horizontais estilo canadense); habitação em alvenaria estrutural; coluna de Gaudi; pergolado em madeira; totens (Kalunga); forno para pizza em terra; bancos com assentos giratórios em madeira; escada com degraus em espiral; arquibancadas em blocos estruturais; abóbora do dia das bruxas em argamassa armada, e tumba da vida eterna.

Na UFSC, especificamente, muitos experimentos vêm sendo conduzidos em espaços abertos, descobertos ou cobertos, por alunos realizando seus trabalhos de conclusão de curso ou associados a laboratórios e disciplinas do curso. Na Figura 5 são apresentados alguns dos experimentos conduzidos no espaço do Departamento de Arquitetura da UFSC, vinculado às disciplinas, como trabalhos de conclusão de curso em Arquitetura e Urbanismo ou de outros cursos como Engenharia Civil ou, fruto de oficinas e atividades extracurriculares promovidas como extensão com comunidade ou integração discente.

Nas Figuras 5 (A), (B) e (C) são ilustrados os protótipos executados no estacionamento do Departamento de Arquitetura, ao lado do LabRestauro/Matec. Todos os protótipos foram montados por alunos e representam sistemas construtivos experimentais para os quais ainda não existem normativas no Brasil. Pode-se destacar o primeiro protótipo que aparece na imagem, constituído por estrutura em bambu e painéis em bahareque, construído pelo estudante de Engenharia Civil, Alexandre Vitor (VITOR, 2018), e já foi alvo de outras publicações (LIBRELOTTO et al., 2019). Para montagem destes protótipos, foram conduzidas diversas oficinas, mutirões, entre outras atividades que envolveram a comunidade, alunos de graduação e de pós-graduação. 
BESSA, S. A. L.; LIBRELOTTO, L. I.

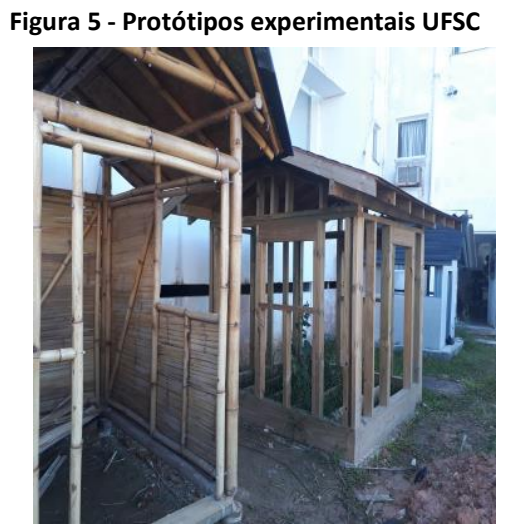

(A) Protótipos experimentas

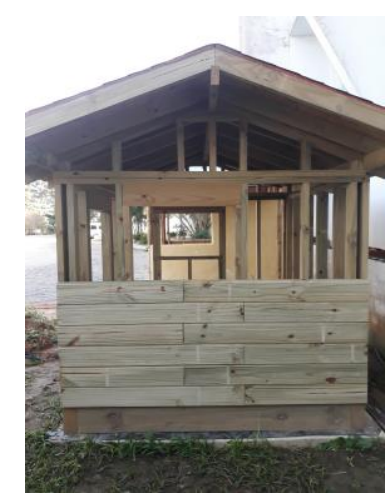

(B) Protótipo em madeira

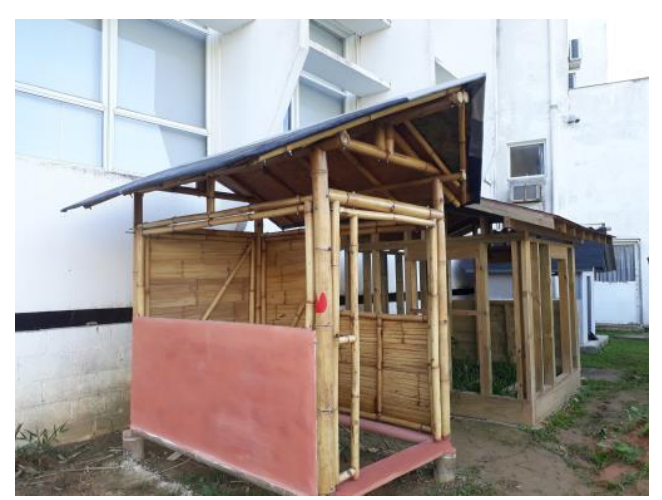

(C) Protótipo em Bambu revestido em terra

Fonte: Lisiane Librelotto (arquivos pessoais).

A Figura 6 (A) representa paredes de hiperadobe, realizadas em trabalho de conclusão de curso em arquitetura e urbanismo, para experimentação de um sistema da cobertura em adobes e teste de sistema de revestimento. As paredes de cord wood na mesma Figura 6 (C) foram realizadas em oficinas conduzidas pelo centro acadêmico e por alunos do curso para construção em mutirão das próprias instalações do centro acadêmico.

Figura 6 - Experimentações realizadas no Departamento de Arquitetura da UFSC

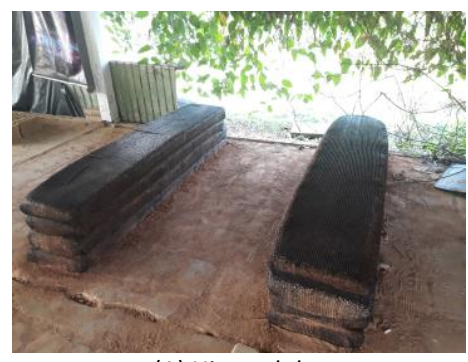

(A) Hiperadobe

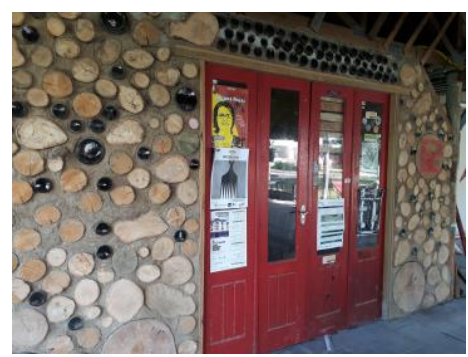

(C) Cord Wood

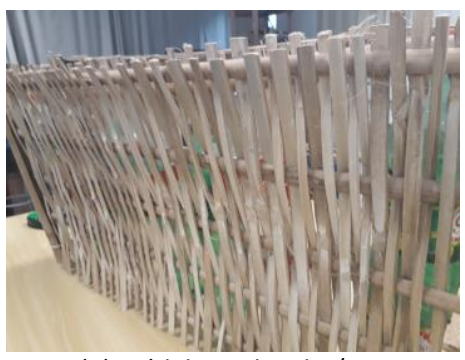

(B) Módulo 1:1 bambu/PET

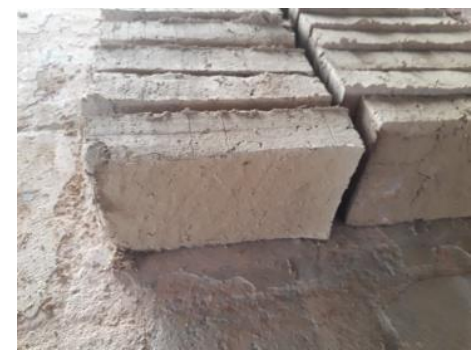

(D) Adobes

Fonte: Lisiane Librelotto (arquivos).

Na Figura 6 (B), apresenta-se um módulo de experimentação para montagem de estrutura e entramado em bambu (somente com encaixes e utilizando pinos/tarugos do próprio material), com preenchimento de garrafas PET (PERDOMO, 2015). Já na imagem 6 (D), os adobes representam as práticas de experimentação reincidentes, realizadas em trabalhos de conclusão, disciplinas e oficinas livres que tantas vezes são realizadas no Departamento.

Para registro histórico e sistematização do conhecimento, destacam-se alguns experimentos conduzidos na disciplina de Tecnologia das Edificações, no curso de Arquitetura e Urbanismo da UFSC (Figura 7, (A) inspiração, (B) objeto realizado). 
BESSA, S. A. L.; LIBRELOTTO, L. I.

A importância das práticas construtivas nos canteiros experimentais em cursos de arquitetura e urbanismo

Figura 7 - Experimento I - Banco à Frank Gehri
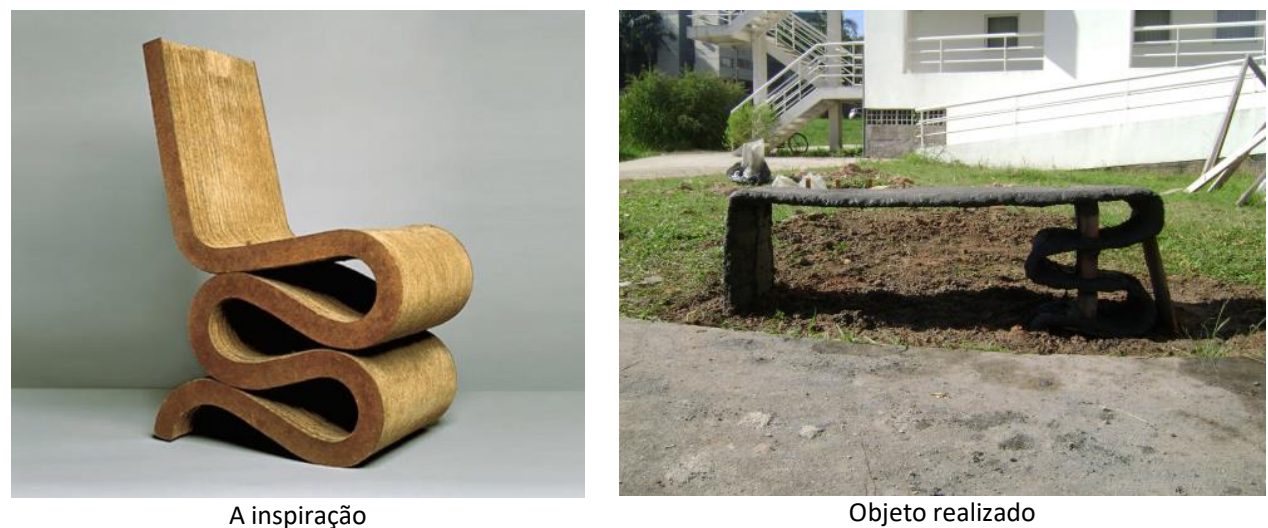

Fonte: Kretzer et al. (2012).

Neste experimento, os alunos realizaram o projeto do equipamento, a locação da posição em que seria construído, o projeto da fundação com detalhamento de formas e armaduras, o estudo e pesquisa do traço para realização da argamassa armada e quantidade de água correta para a mistura. Em função das pequenas espessuras, o grupo sentiu dificuldade de argamassar algumas partes, assim como, atestou a dificuldade de estabilidade da forma proposta sem que as curvas se tocassem. $O$ projeto teve de ser modificado pela introdução de pontos de contato nas curvas.

A espreguiçadeira (Figura 8) constitui-se do projeto seguido do trabalho de execução de dois blocos de fundação, confecção de fôrmas e armaduras, concretagem e acabamento.

Figura 8 - A espreguiçadeira. Experimento II

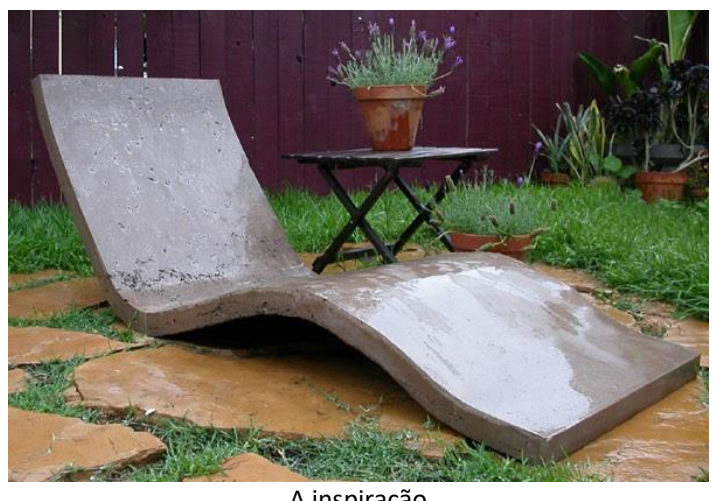

A inspiração

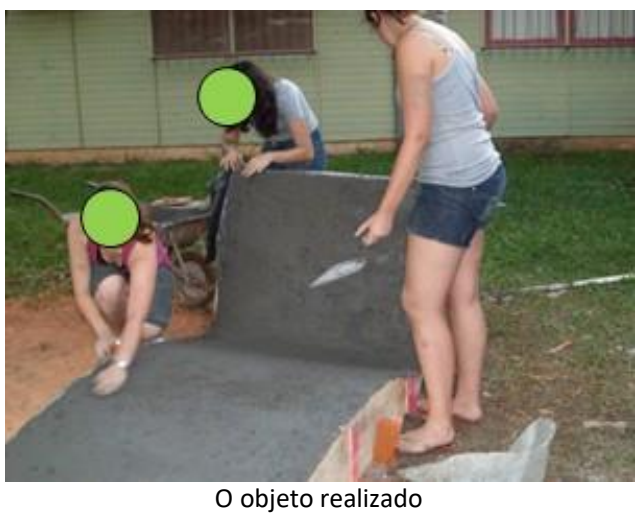

O objeto realizado

Fonte: Mayer et al. (2012).

No experimento do banco, as acadêmicas que elaboraram a proposta relatam diferenças ocorridas entre o projeto e a execução e dificuldades de prever o tempo de realização das atividades. Apontam para problemas na execução das fôrmas de concretagem da fundação, desconhecimento do tempo de cura da concretagem de pilares e despreparo no uso de equipamentos ou realização manual das atividades, devido ao peso do material. Também foram relatados problemas na realização de amarração entre tijolos da vedação (Figura 9).

Para as acadêmicas, os trabalhos evidenciaram a importância das atividades práticas e de todos os conteúdos estudados, como a organização da obra, o detalhamento de projeto e o uso de equipamentos de segurança na realização das atividades. Mais do que tudo, fica a certeza de que o papel aceita tudo e a caneta é capaz de muitas 
BESSA, S. A. L.; LIBRELOTTO, L. I.

A importância das práticas construtivas nos canteiros experimentais em cursos de arquitetura e urbanismo

possibilidades na alvura do plano. Na prática, é necessário traduzir para a realidade de quem executa, por vezes mal treinado, sem instrução ou conhecimento do novo e do todo.

Figura 9 - Experimento III - O banco em madeira, concreto e tijolos - o banco
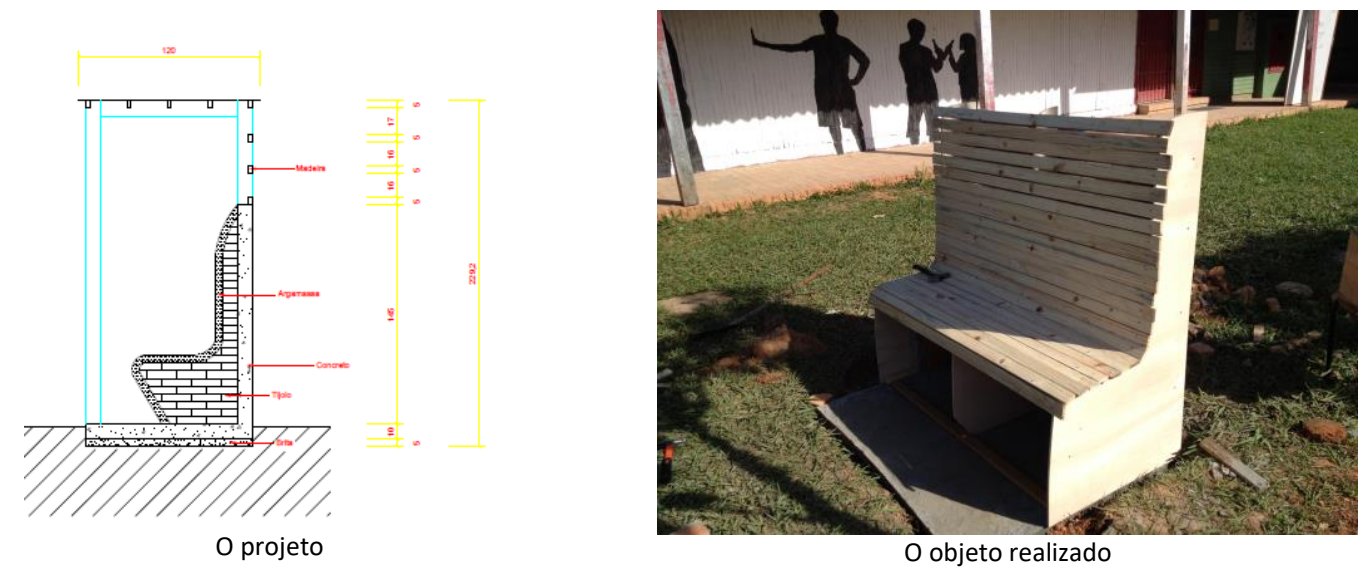

Fonte: Locks et al. (2012).

\section{Discussões}

Após a análise dos principais autores sobre o tema, e das experiências de experimentação prática em cursos de arquitetura, percebe-se que os canteiros experimentais, inseridos em Instituições de Ensino, deveriam apresentar alguns requisitos que devem ser observados na busca do sucesso dos experimentos:

a) Necessidade de salas de aula tradicionais e/ou ateliers que abriguem as aulas teóricas junto ao Canteiro Experimental;

b) As atividades podem ser consideradas extras (eletivas/optativas), estarem vinculadas às disciplinas projetuais, integradas ao currículo ou como atividades complementares a este;

c) As atividades também podem ser conduzidas individualmente, em disciplinas, trabalhos de conclusão de curso, oficinas, práticas, mas desta última devem participar equipes de mais de um integrante;

d) Alguns autores, a exemplo de Ronconi (2002), apontam para que as experiências desenvolvidas no Canteiro Experimental não devam ser parte integrante do currículo, portanto, não poderão substituir os ensaios e experimentos tradicionais relacionados a materiais e técnicas construtivas, instalações domiciliares e outras. Entretanto, pela DCNs para os CAU, nada impede que algumas disciplinas do curso, voltadas à tecnologia das edificações, sistemas e processos construtivos, tenham parte de seu ementário desenvolvido com apoio dos canteiros experimentais, principalmente no que se refere ao uso do material de formas não-convencionais ou usuais;

e) Observou-se alguns canteiros experimentais formalmente constituídos e vinculados a estruturas curriculares nos projetos pedagógicos;

f) Nos relatos, percebe-se a integração do canteiro com as atividades de pesquisa da graduação, pós-graduação, como também com as atividades de extensão;

g) As áreas destinadas aos canteiros necessitam do apoio de espaços cobertos e áreas descobertas, com e sem pavimentação; 
BESSA, S. A. L.; LIBRELOTTO, L. I.

A importância das práticas construtivas nos canteiros experimentais em cursos de arquitetura e urbanismo

h) Também se considera importante que os canteiros sejam utilizados por diferentes disciplinas todos os anos; dessa forma, o aluno pode ter acesso ao espaço em vários momentos ao longo da sua formação e isso poderá reforçar as qualidades pedagógicas de maneira efetiva (LOTUFO, 2014).

Muitos cursos têm inserido as atividades em canteiro experimental em disciplinas curriculares ou complementares. Quanto à pertinência ou não das atividades no canteiro experimental, verifica-se que alguns autores as vinculam quase que exclusivamente a atividades de concepção criativa, com uma ênfase bastante forte voltada à concepção estrutural. Outros autores excluem a produção de protótipos e chegam a relacionar atividades que não poderiam ser enquadradas como atividades do canteiro experimental.

\section{Considerações finais}

As atividades práticas que são desenvolvidas em canteiros experimentais, formais ou informais, recebem este nome ou não. Constituem-se de atividades voltadas ao ensino, à pesquisa e à extensão e podem promover atividades multidisciplinares, como aproximar vários cursos e fortalecer a ligação da universidade com a comunidade das mais diversas formas. Neste trabalho foram apresentados e discutidos relatos que envolveram tanto os alunos como a comunidade externa- Tais experimentos foram oportunidades de aprendizagem, de fortalecimento de redes e de criação de vínculos e de compartilhamento do conhecimento entre os participantes.

Nos depoimentos e referências encontradas, sobretudo nas práticas em canteiros experimentais, percebeu-se que as visões convergem apenas no sentido de que o canteiro experimental deve abordar atividades criativas e que fogem daquelas desenvolvidas nos canteiros e laboratórios tradicionais de materiais e de construção civil. No experimento, o resultado não é tão importante quanto o aprendizado.

Os pontos mais divergentes referem-se à necessidade de formalização do canteiro nos respectivos cursos de arquitetura e urbanismo. Alguns autores colocam a atividade como paralela à formação do arquiteto, outros como complementar e alguns como atividade que deve ser formalizada e integrada ao currículo, havendo nos casos estudados, representantes de todas estas situações.

No entanto, pode-se entender que os canteiros experimentais são espaços eficientes e eficazes, capazes de fomentar o desenvolvimento de atividades criativas e inovadoras, além de possibilitar a existência de relações professor/aluno mais dialógicas.

\section{Referências}

AMARAL, B. Da crítica do canteiro à autogestão: Sérgio Ferro, Usina e os mutirões autogeridos em São Paulo. Brasil: Finisterra, v. 55, n. 114, p. 141-155, 2020. Disponível em: https://revistas.rcaap.pt/finisterra/article/view/19631. DOI: https://DOI.org/10.18055/Finis19631

ARANTES, P. F. Arquitetura Nova: Sérgio Ferro, Flávio Império e Rodrigo Lefèvre, de Artigas aos mutirões, Posfácio de Roberto Schwarz. São Paulo: Editora 34, 2002. 256 p.

ARTIGAS, Vilanova. A função social do arquiteto. São Paulo: Nobel, 1989.

ARTIGAS, Vilanova. Caminhos da arquitetura. São Paulo: Cosac Naify, 2004.

BENOIT, L. O. Arquitetura e luta de classes: uma entrevista com Sérgio Ferro. Crítica Marxista, Campinas, n. 15, p. 140-150. 2002. Disponível em: 
BESSA, S. A. L.; LIBRELOTTO, L. I.

A importância das práticas construtivas nos canteiros experimentais em cursos de arquitetura e urbanismo

https://www.ifch.unicamp.br/criticamarxista/sumario.php?id_revista=15\&numero_revista=15. Acesso em: 19 ago. 2021.

BESSA, S. A. L.; LOPES, M. S. B.; LOURA, R. M. Associação de práticas projetuais e construtivas associadas no ensino de arquitetura. In: CONGRESO ARQUISUR: LA DIMENSIÓN PÚBLICA DE LA ARQUITECTURA, 22, 2018, Rosário. Libro de Ponencias [...]. Rosario: A\&P Ediciones, 2018. Disponível em: https://fapyd.unr.edu.ar/wpcontent/uploads/2019/02/libro_ponencias_arquisur-1.pdf. Acesso em nov. 2019.

BORBA, I. M. de M. Ensino de arquitetura e urbanismo - UTFPR na prática. 2018. Tese (Doutorado em Tecnologia da Arquitetura) - Faculdade de Arquitetura e Urbanismo, Universidade de São Paulo, São Paulo, 2018. DOI: https://DOI.org/10.11606/T.16.2019.tde-17012019-145820. Acesso em: 2020-07-09.

BORGES, A. Fim do 'platô' mobiliza alunos da FAU. Jornal da PUC Campinas. 11 a 24 de Abril de 2005. Disponível em: https://www.puc-campinas.edu.br/ handlers/arquivos/?arquivo=369, Acesso em: nov. 2019.

BRASIL. MINISTÉRIO DO TRABALHO E EMPREGO. Norma Regulamentadora 18 - Condições e Meio Ambiente de Trabalho na Indústria da Construção. 2020. Disponível em: https://www.gov.br/trabalho-e-previdencia/ptbr/composicao/orgaos-especificos/secretaria-de-trabalho/inspecao/seguranca-e-saude-no-trabalho/normasregulamentadoras/nr-18-atualizada-2020.pdf/view

CANTEIRO ESCOLA CTBC. Canteiro-Escola / HABIS. Facebook: Canteiro Escola CTBC. Disponível em: https://www.facebook.com/canteiroescolatcbc. Acesso em: nov. 2019.

CANTEIRO EXPERIMENTAL. [s.n], 1994. 1 vídeo (4 minutos). Publicado pelo canal FAUUSP. Disponível em: https://www.youtube.com/watch?v=uG10ifTIhQM . Acesso em 08 jul. 2020

CEAU - COMISSÃO DE ESPECIALISTAS DE ENSINO DE ARQUITETURA. Perfis da Área \& Padrões de Qualidade. Expansão, Reconhecimento e Verificação Periódica dos Cursos de Arquitetura e Urbanismo. Ministério da Educação. Secretaria da Educação Superior. 1994. Disponível em: http://portal.mec.gov.br/sesu/arquivos/pdf/ar_geral.pdf. Acesso em: nov. 2019.

DIEDERICHSEN, F. T. B. Formação Profissional na construção civil: experiências em busca da 'desalienação' do trabalho. 2012. Dissertação (Mestrado em Tecnologia da Arquitetura) - Faculdade de Arquitetura e Urbanismo, Universidade de São Paulo, São Paulo, 2012. DOI: 10.11606/D.16.2012.tde-12112012-125742. Acesso em: abr.2021.

EVEN3. Seminário Canteiro Experimental em Arquitetura e Urbanismo. Disponível em:

https://www.even3.com.br/canteiroexperimental/ Acesso em: jul. 2020.

FAAC-UNESP - FACULDADE DE ARQUITETURA, ARTES, COMUNICAÇÃO E DESIGN -UNIVERSIDADE ESTADUAL PAULISTA - FAAC/UNESP. Arquitetura e Urbanismo - Estrutura Curricular Semestral. Disponível em: https://www.faac.unesp.br/\#!/graduacao/cursos/arquitetura-e-urbanismo/laboratorios-didaticos/. Acesso em: set.2021

FAENG - FACULDADE DE ARQUITETURA, ENGENHARIA E GEOGRAFIA - UNIVERSIDADE FEDERAL DO MATO GROSSO DO SUL. Canteiro Experimental, [s.n.]. Disponível em: https://faeng.ufms.br/graduacao/bacharelado/arquitetura-eurbanismo/bloco-de-arquitetura-e-urbanismo/canteiroexperimental/. Acesso em set. 2021.

FAU-MACKENZIE - FACULDADE DE ARQUITETURA E URBANISMO/ UNIVERSIDADE MACKENZIE. Data histórica: inaugurado canteiro experimental. São Paulo: Faculdade de Arquitetura e Urbanismo, Universidade Presbiteriana Mackenzie, 2014. Disponível em: https://faumack.wordpress.com/2014/05/15/data-historica-inaugurado-canteiroexperimentall. Acesso em set. 2021.

FAU-UFRJ - FACULDADE DE ARQUITETURA E URBANISMO/ UNIVERSIDADE FEDERAL DO RIO DE JANEIRO. Laboratórios - LEMC - Laboratório de Ensaios de Materiais de Construção e Estudo do Solo. Disponível em: http://www.fau.ufri.br/laboratorios/.Acesso em: set. 2021. 
BESSA, S. A. L.; LIBRELOTTO, L. I.

A importância das práticas construtivas nos canteiros experimentais em cursos de arquitetura e urbanismo

FAU-USP - FACULDADE DE ARQUITETURA E URBANISMO/ UNIVERSIDADE DE SÃO PAULO. Canteiro de Espaços Experimentais para a Arquitetura "Antonio Domingos Battaglia", 2019. Disponível em:

http://www.fau.usp.br/apoio/canteiro-experimental . Acesso em: nov. 2019.

FECFAU-UNICAMP - FACULDADE DE ENGENHARIA CIVIL E ARQUITETURA -UNIVERSIDADE ESTADUAL DE CAMPINAS. Regimento do COE - aprovação. Disponível em: https://www.fec.unicamp.br/arqs/20180920075016Pauta.pdf. Acesso em: nov. 2019.

FERRO, S. Experimentação em arquitetura: práxis crítica e reação conservadora. In: RONCONI, R. L. N. et al. (Org.). Canteiro experimental - 10 anos na FAU. 1. São Paulo: FAU/USP, 2008, p. 19-23.

HABIS. Grupo de Pesquisa em Habitação e Sustentabilidade. Disponível em: https://www.iau.usp.br/pesquisa/grupos/habis/. Acesso em: jul. 2020.

KRETZER, G.; MORETTO, L. R. ; MARCELINO, L. A. ; RITZMANN, P. Tecnologias das edificações II. -- Lisiane Ilha Librelotto. Florianópolis : UFSC, 2012. Relatório [acesso restrito].

LIBRELOTTO, L.; OSTAPIV, F.; VITOR, A. O.; JARAMILLO, A. B.; FERROLI, P. C. M.; BERALDO, A. L.; SALAMON, C.; SANTOS, G. F. DOS; SASAOKA, S.; LISBOA, S.; CARBONARI, G.; OSTAPIV, J. P. DA S.; BARATA, T. Q. F.; PEREIRA, M. A. Bambu: Caminhos para o Desenvolvimento Sustentável. Florianópolis: UFSC/Virtuhab, 2019. Disponível em: https://repositorio.ufsc.br/handle/123456789/197060.

LOCKS, B.; BECEL, B.; MEIRA B.: MENEGON, B.; WIGERS, C. Tecnologias das edificações II. -- Lisiane Ilha Librelotto. Florianópolis : UFSC, 2012. Relatório [acesso restrito].

LOPES, M. S. B.; LOURA, R. M; BESSA, S. A. L. Práticas projetuais e construtivas associadas no ensino da construção com terra. In: CONGRESSO DE ARQUITETURA E CONSTRUÇÃO COM TERRA, 7, 2018. Anais [...]. Rio de Janeiro: Rede Terra Brasil, 2018.

LOTUFO, T. A. Um novo ensino para outra prática: Rural Studio e Canteiro Experimental, contribuições para o ensino de arquitetura no Brasil. 2014. Dissertação (Mestrado em Habitat) - Faculdade de Arquitetura e Urbanismo, Universidade de São Paulo, São Paulo, 2014. DOI: 10.11606/D.16.2014.tde-29052014-153721. Acesso em: abr.2021.

MAYER, J; CAROLINA, F.; DUARTE, L; KLEIN, M. Tecnologias das edificações II. -- Lisiane Ilha Librelotto. Florianópolis : UFSC, 2012. Relatório as built [acesso restrito].

MEC - MINISTÉRIO DA EDUCAÇÃO E CULTURA. Cadastro Nacional de Cursos e Instituições de Educação Superior Cadastro e-MEC. Disponível em: https://emec.mec.gov.br/ . Acesso em: abr. 2021.

MINTO, F. C. N. A experimentação prática construtiva na formação do arquiteto. 2009. Dissertação (Mestrado em Tecnologia da Arquitetura) - Faculdade de Arquitetura e Urbanismo, Universidade de São Paulo, São Paulo, 2009. DOI: 10.11606/D.16.2009.tde-26042010-152603. Acesso em: nov.2019.

NASCIMENTO, A. C.; SILVOSO, M. M.; GONÇALVES, J. P. O canteiro experimental como estratégia de ensino de estruturas. In: ENCONTRO NACIONAL DE ENSINO DE ESTRUTURAS EM ESCOLAS DE ARQUITETURA, 3, 2017. Anais [...]. Ouro Preto: Editora da UFOP, 2017. p. 810-825.

LIBRELOTTO, L. I.; PERDOMO, L. D. Projeto Florescer - Habitação de Interesse Social Incorporando Materiais Locais e Resíduos Sólidos. Mix Sustentável, v. 1, n. 2, p. 151-153, 2015.

PISANI, M. A. J.; CALDANA, V.; CORRÊA, P. R.; VILLÁ, J.; AMODEO, V. O ensino do projeto de arquitetura e urbanismo: um canteiro experimental. In: PROJETAR - Projeto como Investigação: Ensino, Pesquisa e Prática, 4, 2009. Anais [...]. FAU Mackenzie: São Paulo, 2009.

POMPÉIA, R. A. Os Laboratórios de Habitação no ensino da arquitetura: uma contribuição ao processo de formação do arquiteto. 2006. Tese (Doutorado em Tecnologia da Arquitetura) - Faculdade de Arquitetura e 
BESSA, S. A. L.; LIBRELOTTO, L. I.

A importância das práticas construtivas nos canteiros experimentais em cursos de arquitetura e urbanismo

Urbanismo, Universidade de São Paulo, São Paulo, 2007. DOI: 10.11606/T.16.2007.tde-18092007-165259. Acesso em: set. 2020.

PUC-CAMPINAS - PONTÍFICIE UNIVERSIDADE CATÓLICA DE CAMPINAS. Atividade complementar: Arquitetura de Baixo Impacto Ambiental. Disponível em: https://www.puc-campinas.edu.br/handlers/arquivos/?arquivo=1864 . Acesso em: nov. 2019.

PUC-MINAS - PONTIFÍCIA UNIVERSIDADE CATÓLICA DE MINAS GERAIS. Canteiro Escola, 2019. Disponível em: https://ipuc.pucminas.br/index.php/extensao/projetos/canteiro-escola/ Acesso em jul. 2020.

PUC-MINAS - PONTIFÍCIA UNIVERSIDADE CATÓLICA DE MINAS GERAIS. O Escritório de Integração dá boas-vindas aos calouros, 2009. Disponível em: http://portal.pucminas.br/pucinforma/materia1.php?codigo=5130 . Acesso em jul. 2020.

PUC-RIO - PONTIFÍCIA UNIVERSIDADE CATÓLICA DO RIO DE JANEIRO. Canteiro experimental - Corte a laser. Disponível em: http://www.dau.puc-rio.br/graduacao/?pageld=98. Acesso em jul. 2020.

PORTAL ANHEMBI. Arquitetura e Urbanismo. Disponível em: https://portal.anhembi.br/graduacao/cursos/arquitetura-e-urbanismo/\#infraestrutura . Acesso em: nov. 2019.

RONCONI, R. L. N. Inserção do Canteiro Experimental nas Faculdades de Arquitetura e Urbanismo. Tese de Doutorado, São Paulo: FAUUSP, 2002.

RONCONI, R. L. N. Canteiro experimental: uma proposta pedagógica para a formação do arquiteto e urbanista. Pós. Revista do Programa de Pós-Graduação em Arquitetura e Urbanismo da FAUUSP, São Paulo, número 17, p. $142-159$. DOI: https://DOI.org/10.11606/issn.2317-2762.voi17p142-159. Acesso em: nov. 2019.

SARAMAGO, R. DE C. P.; LOPES, J. M. DE A. Ensino de estruturas nas escolas de arquitetura do Brasil: estrutura curricular e recursos didáticos. Revista Tecnológica, p. 169-179, 8 jan. 2010.

SILVOSO, M. M.; CORDEIRO, P. C.; ALBUQUERQUE, R. T. O ato de construir como uma ação integradora de conteúdos no canteiro experimental da FAU/UFRJ. In: ENCONTRO NACIONAL DE ENSINO DE ESTRUTURAS EM ESCOLAS DE ARQUITETURA, 3, 2017, Ouro Preto. Anais [...]. Ouro Preto: Editora da UFOP, 2017. p. 319-418.

TECTÔNICA. Faculdade de Arquitetura. Universidade Federal da Bahia. Grupo Tectônica. Disponível em: http://www.tectonica.ufba.br Acesso em jul. 2020.

UEMA - UNIVERSIDADE ESTADUAL DO MARANHÃO. Projetos de Pesquisa Aprovados. Disponível em: https://www.ppg.uema.br/wp-content/uploads/2017/06/PROJETOS-DE-PESQUISA-DE-BOLSAS-DESUSTENTABILIDADE-2017-CONTEMPLADOS.pdf. Acesso em jul. 2020.

UFFS - UNIVERSIDADE FEDERAL DA FRONTEIRA SUL. PPC do Curso de Graduação em Arquitetura e Urbanismo Campus Erechim (Ingressos a partir de 2016), 2016. Disponível em: https://www.uffs.edu.br/atos-

normativos/ppc/ccauer/2016-0002. Acesso em 08 jul. 2020.

UFG - UNIVERSIDADE FEDERAL DE GOIÁS -. PPC do Curso de Arquitetura e Urbanismo da Regional de Goiás. Disponível em: https://files.cercomp.ufg.br/weby/up/190/o/PPC_CAU_2017_\%281\%29.pdf. Acesso em 08 jul. 2020.

UFPR - UNIVERSIDADE FEDERAL DO PARANÁ. Curso de arquitetura e urbanismo - Disciplinas do curso. Disponível em: http://www.cau.ufpr.br/portal/disciplinas/. Acesso em nov. 2019.

VITOR, A. O. Proposta de Habitação de Interesse Social (HIS) em estrutura de bambu: projeto e construção de um protótipo experimental. CC (graduação) - Universidade Federal de Santa Catarina. Centro Tecnológico. Engenharia Civil. 2018. Disponível em: https://repositorio.ufsc.br/handle/123456789/192366 
BESSA, S. A. L.; LIBRELOTTO, L. I.

A importância das práticas construtivas nos canteiros experimentais em cursos de arquitetura e urbanismo

\section{${ }^{1}$ Sofia Araújo Lima Bessa}

Arquiteta e Urbanista. Doutora em Engenharia Urbana. Escola de Arquitetura da Universidade Federal de Minas Gerais. Programa de Pós-graduação em Ambiente Construído e Patrimônio Sustentável (PPG-ACPS). Endereço postal: Rua Paraíba, 697, sala 313, Belo Horizonte, MG, Brasil, CEP 30130-141.

\section{${ }^{2}$ Lisiane Ilha Librelotto}

Engenheira Civil. Doutora em Engenharia de Produção. Departamento de Arquitetura e Urbanismo. Programa da Pósgraduação em Arquitetura e Urbanismo - PósARQ. Grupo de Pesquisa Virtuhab/ Labrestauro/Matec. Endereço postal: Depto. de Arquitetura e Urbanismo // CTC-UFSC // Campus Trindade - CP 470 - CEP 88040-970 - Florianópolis - Santa Catarina - Brasil. 